\title{
Nordic research on per- and polyfluoroalkyl substances (PFASs)
}

\author{
Ian T. Cousins
}

Received: 23 April 2013 / Accepted: 10 July 2013 /Published online: 21 September 2013

(C) Springer-Verlag Berlin Heidelberg 2013

This special issue of Environmental Science and Pollution Research (ESPR) comprises this editorial and a collection of 12 original research papers from research groups that are members of the NordForsk Network for Fluorinated Compounds (acronym Nordfluor). The Nordfluor network is a researcher network financed by NordForsk (an organisation under the Nordic Council of Ministers that provides funding for Nordic research cooperation) that aims to bring together prominent research groups working on fluorinated compounds in the Nordic and Baltic countries in order to strengthen and increase the quality of research and research training. Nordfluor comprises 22 individual research groups and approximately 100 researchers from Denmark, Finland, Germany, Iceland, Norway and Sweden. Nordfluor has the following specific aims:

1. To integrate the expertise of the 22 research groups in the Nordic region (in Sweden, Denmark, Norway, Island and Finland) and Germany who have complementary expertise in the research on fluorinated compounds and, through this, strengthen the competitiveness of Nordic (and thus also European) research.

2. To train graduate students and researchers (at all levels) in complementary research methods not available to them at their institution through exchange grants to increase the pool of highly qualified researchers with expert knowledge in this field.

3. To encourage network partners to share knowledge, facilities, materials and methods and thus increase the possibilities for undertaking novel research.

4. To organise scientific symposia, including scientific presentations, workshops and short courses. The workshops are used to identify areas for research cooperation.

Responsible editor: Philippe Garrigues

I. T. Cousins $(\bowtie)$

Department of Applied Environmental Science (ITM), Stockholm

University, 10691 Stockholm, Sweden

e-mail: ian.cousins@itm.su.se
5. To develop new graduate courses focused on training students in different aspects of fluorinated chemical research.

6. To foster long-term research relationships that will continue beyond the funding of Nordfluor and lead to future funding applications for collaborative projects.

7. To increase awareness of research undertaken within the network to the scientific community, regulatory and industry stakeholders as well as amongst the general public.

This special issue is part of Nordfluor's dissemination activities (objective 7).

The Nordfluor network chose to include the very general and non-specific "fluorinated compounds" in its full name, which describes a universe of organic and inorganic substances that contain at least one F atom. Usually in our research, and certainly in this special issue, the Nordfluor members focus on a subset of fluorinated compounds known as "perfluoroalkyl and polyfluoroalkyl substances" (PFASs). PFASs are highly fluorinated aliphatic substances that contain one or more C atoms on which all the $\mathrm{H}$ substituents (present in the nonfluorinated analogues from which they are notionally derived) have been replaced by $\mathrm{F}$ atoms, in such a manner that they contain the perfluoroalkyl moiety $\mathrm{C}_{n} \mathrm{~F}_{2 n+1}$ (Buck et al. 2011).

PFASs have been manufactured since the 1950s and used in industrial and commercial applications including in protective coatings (for paper, carpets, textiles and leathers), lubricants, paints, cosmetics, surfactants and firefighting foams (Kissa 2001). However, it was only since the turn of the millennium that researchers discovered some of the environmental and human health problems associated with this class of substances. The carbon-fluorine bond has one of largest bond energies in nature, which causes some PFASs to be extremely stable and thus persistent in the environment. Scientists and regulators have, in particular, focused much attention on perfluoroalkane sulfonic acids (PFSAs) and perfluoroalkyl carboxylic acids (PFCAs), and especially on 
the long-chain PFSAs $\left(\mathrm{C}_{n} \mathrm{~F}_{2 n+1} \mathrm{SO}_{3} \mathrm{H}, n \geq 6\right)$ and PFCAs $\left(\mathrm{C}_{n} \mathrm{~F}_{2 n+1} \mathrm{COOH}, n \geq 7\right)$, which have been shown to be bioaccumulative. Perfluorooctane sulfonate (PFOS) and perfluorooctanoic acid (PFOA) are the two most well-known and studied substances amongst the perfluoroalkyl acids (PFAAs). As a consequence of the persistence and bioaccumulation potential of long-chain PFAAs in combination with their global use and emission for many decades, these substances have been shown to be globally present in the environment (e.g. Yamashita et al. 2008), wildlife (e.g. Giesy and Kannan 2001) and humans (e.g. Hansen et al. 2001). They have also been shown to have a range of toxicological effects in laboratory animals (Lau et al. 2007), and thus there are concerns about the potential risks to human health.

The persistence, bioaccumulation potential and possible toxicological effects of long-chain PFAAs have led to a number of actions by regulators and industry. In 2001, the $3 \mathrm{M}$ Company, a leading global manufacturer of PFASs, decided that they would phase out the production of PFOS, PFOA and related substances with C6, C8 and C10 "chemistry" (i.e. those PFASs with perfluorinated chains with six to ten carbons) and replace them with products with only four perfluorinated carbons. Since the 3M's historical decision, other major manufacturers have also progressively replaced PFASs containing long-chain perfluoroalkyl moieties with products containing shorter perfluoroalkyl chains. Global regulation has also been introduced, for example, the inclusion of PFOS in the Stockholm Convention on Persistent Organic Pollutants as an Annex B substance, i.e. restricted in its use (UNEP 2009). Although the manufacture and use of long-chain PFAAs is more and more restricted in Europe and North America, new manufacturers (largely in Asia) have begun to produce long-chain PFAAs and their precursors (substances that degrade to form PFAAs).

The Nordic countries contain an abundance of pristine environments (including the Arctic) that need protection. Persistent, bioaccumulative and toxic chemicals are often being transported into the Nordic region from neighbouring countries, sometimes by unknown mechanisms, and the increasing presence of toxic chemicals in pristine environments such as the Arctic is of concern. It is therefore imperative that we better understand the sources, fate, exposure and effects (wildlife and human) of existing PFASs as well as potential replacements. Understanding the environmental behaviour of PFASs is a significant scientific challenge because PFASs have unique properties and thus behave differently from the classical hydrophobic organic pollutants (Prevedouros et al. 2006). The environmental sciences, especially the field of environmental chemistry, are particularly important and strong research areas in the Nordic countries. In the last decade, the amount of research focusing on PFASs has increased exponentially, and now several hundred research articles are published in the field each year. The
Nordic countries have been involved in PFAS research from the early stages and have made some vital contributions. Examples are the following:

- Some of the pioneering analytical work to detect PFASs in Arctic wildlife was undertaken by Danish researchers (Bossi et al. 2005; Dietz et al. 2008).

- Another group of Danish researchers were among the pioneers in understanding the atmospheric chemistry of precursor compounds (Wallington et al. 2006).

- The Nordic region has globally leading analytical groups who have developed novel ultra-trace analytical methods for a range of environmental and biological matrices (e.g. Berger et al. 2011).

- Scientists based at Stockholm University made the first estimates of global source emissions of PFCAs (Prevedouros et al. 2006) and undertook the first global multimedia modelling of PFOA (Armitage et al. 2006). Scientists from the same group also collaborated with Swiss scientists to make the first estimates of human exposure to PFOS and PFOA from multiple pathways (Trudel et al. 2008) and later also considered indirect exposure from intake and metabolism of precursors (Vestergren et al. 2008).

This special issue of ESPR contains a selection of the diverse ongoing research being undertaken by the members of the Nordfluor network on analytical methods, monitoring, environmental fate, aquatic and terrestrial bioaccumulation, ecotoxicology and human exposure and human health. There are 12 original research papers contributed by authors from five of the countries (Sweden, Denmark, Norway, Finland and Germany) represented in Nordfluor, which are summarised briefly below.

Several papers in the ESPR special issue focus on human exposure to PFASs from diet. Herzke et al. (2013) monitor concentrations in commonly consumed vegetables from four European countries and conclude that consumption of vegetables is a relatively unimportant human exposure pathway for long-chain PFAAs. Eriksson et al. (2013) analyse PFASs in the human diet and drinking water from the Faroe Islands, which are some of the first data reported for this region. Gebbink et al. (2013) demonstrate that perfluoroalkyl phosphate diesters (diPAPs) are commonly present in Swedish food packaging materials and food samples. They further conclude that diPAPs could be an important indirect source of human exposure to PFCAs. Vestergren et al. (2013) focus on how beef and dairy food products are contaminated with PFAAs through bioaccumulation in agricultural food chains by conducting a mass balance of PFAAs for a herd of dairy cows in a barn on a typical Swedish dairy farm. Ode et al. (2013) focus on another potential pathway of human exposure that is poorly understood, namely foetal exposure, by investigating the relationships between the levels of PFAAs in paired maternal and cord serum samples.

Three contributions in this special issue consider the sources and aquatic fate of PFASs. Perkola and Sainio (2013) identify 
and quantify sources of PFAAs to surface waters and, ultimately, the Baltic Sea from wastewater effluents, storm water runoff and landfill leachate. Xie et al. (2013) simultaneously measure a range of neutral PFASs in the air and seawater of the North Sea to better understand the sources and fate of these substances. Keränen et al. (2013) performed laboratory experiments to demonstrate that fluorotelomer alcohols can be microbially degraded to form PFCAs in brackish waters.

Two studies in the special issue focus on bioaccumulation in wildlife. Galatius et al. (2013) measured the contaminant profiles of a range of PFASs in three marine mammal species (white-beaked dolphin, harbour porpoise and harbour seals) from the North Sea and observed some interesting species differences in bioaccumulation behaviour. Nordén et al. (2013) studied the transfer of PFAAs from eggs to developing chicks in two wild bird species (great cormorant and herring gull). Relatively high levels of PFAAs were observed in all tissues analysed for both species, with the highest levels observed in egg yolks of cormorants.

Two papers consider the effects of PFAAs on human health. Kjeldsen and Bonefeld-Jørgensen (2013) elucidate the mechanisms behind PFAS interference with steroid hormone receptor functions and conclude that some PFASs possess the potential in vitro to interfere with the function of the oestrogen receptor and/or the androgen receptor. Long et al. (2013) study the effect of PFASs on the thyroid hormone function and concluded that PFASs possess in vitro endocrine-disrupting potential by interfering with both the thyroid hormone system and aryl hydrocarbon receptor.

I am proud to be a coordinator of Nordfluor because we have some of the world's leading experts on PFAS research located at organisations within the network and also because we cover such a wide range of disciplines within "contaminant science." I hope you, too, will look forward to reading this special issue for an update on the latest Nordic research in this exciting field.

Acknowledgments All members of the Nordic Network for Research on Fluorinated Compounds (Nordfluor) would like to thank NordForsk (an organisation under the Nordic Council of Ministers) for providing funding for this Nordic Researcher Network. We are also grateful to the ESPR Editorial Board and reviewers for undertaking the careful review of manuscripts submitted to the special issue.

\section{References}

Armitage J, Cousins IT, Buck RC, Prevedouros K, Russell MH, MacLeod M, Korzeniowski SH (2006) Modeling global-scale fate and transport of perfluorooctanoate emitted from direct sources. Environ Sci Technol 40:6969-6975

Berger U, Kaiser MA, Kärrman A, Barber JL, van Leeuwen SPJ (2011) Recent developments in trace analysis of poly- and perfluoroalkyl substances. Anal Bioanal Chem 400:1625-1635
Bossi R, Riget F, Dietz R (2005) Temporal and spatial trends of perfluorinated compounds in ringed seal (Phoca hispida) from Greenland. Environ Sci Technol 39:7416-7422

Buck RC, Franklin J, Berger U, Cousins IT, de Voogt P, Astrup Jensen A, Kannan K, Mabury SA, van Leeuwen S (2011) Perfluoroalkyl and polyfluoroalkyl substances in the environment: terminology, classification, and origins. Int Environ Assess Man 7(4):513-541

Dietz R, Bossi R, Riget FF, Sonne C, Born EW (2008) Increasing perfluoroalkyl contaminants in east Greenland polar bears (Ursus maritimus): a new toxic threat to the Arctic bears. Environ Sci Technol 42(7):2701-2707

Eriksson U, Kärrman A, Rotander A, Mikkelsen B, Dam M (2013) Perfluoroalkyl substances (PFASs) in food and water from Faroe Islands. Environ Sci Pollut Res. doi:10.1007/s11356-013-1700-3

Giesy JP, Kannan K (2001) Global distribution of perfluorooctane sulfonate in wildlife. Environ Sci Technol 35:1339-1342

Gebbink WA, Ullah S, Sandblom O, Berger U (2013) Polyfluoroalkyl phosphate esters and perfluoroalkyl carboxylic acids in target food samples and packaging - method development and screening. Environ Sci Pollut Res. doi:10.1007/s11356-013-1596-y

Galatius A, Bossi R, Sonne C, Rigét FF, Kinze CC, Lockyer C, Teilmann J, Dietz R (2013) PFAS profiles in three North Sea top predators: metabolic differences among species? Environ Sci Pollut Res. doi:10.1007/s11356-013-1633-x

Hansen KJ, Clemen LA, Ellefson ME, Johnson HO (2001) Compoundspecific, quantitative characterization of organic: fluorochemicals in biological matrices. Environ Sci Technol 35:766-770

Herzke D, Huber S, Bervoets L, D’Hollander W, Hasjlova J, Pulkrabova J, Brambilla G, De Fillippis SP, Klenow S, Heinemeyer G, de Voogt P (2013) Perfluorinated alkylated substances in vegetables collected in four European countries; occurrence and human exposure estimations. Environ Sci Pollut Res. doi:10.1007/s11356-013-1777-8

Kissa E (2001) Fluorinated surfactants and repellents, 2nd, Ed. Markel Dekker, New York

Kjeldsen LS, Bonefeld-Jørgensen EC (2013) Perfluorinated compounds affect the function of sex hormone receptors. Environ Sci Pollut Res. doi: $10.1007 / \mathrm{s} 11356-013-1753-3$

Keränen J, Akhola H, Knuutinen J, Herve S, Reinikainen M, Koistinen J (2013) Formation of PFOA from 8:2 FTOH in closedbottle experiments with brackish water. Environ Sci Pollut Res. doi:10.1007/ s11356-013-1975-4

Long M, Ghisari M, Bonefeld-Jørgensen EC (2013) Effects of perfluoroalkyl acids on the function of the thyroid hormone and the aryl hydrocarbon receptor. Environ Sci Pollut Res. doi:10.1007/s11356-013-1628-7

Lau K, Anitole C, Hodes D, Lai A, Pfahles-Hutchens A, Seed J (2007) Perfluoroalkyl acids: a review of monitoring and toxiclogical findings. Toxicol Sci 99(2):366-394

Nordén M, Berger U, Engwall M (2013) High levels of perfluoroalkyl acids in eggs and embryo livers of great cormorant (Phalacrocorax carbo sinensis) and herring gull (Larus argentatus) from Lake Vänern, Sweden. Environ Sci Pollut Res. doi:10.1007/s11356-013-1567-3

Ode A, Rylander L, Lindh CH, Källén K, Jönsson BAG, Gustafsson P, Olofsson P, Ivarsson, SA, Rignall-Hydbom A (2013) Determinants of maternal and fetal exposure and temporal trends of perfluorinated compounds. Environ Sci Pollut Res. doi:10.1007/s11356-013-1573-5

Perkola N, Sainio P (2013) Survey of perfluorinated alkyl acids in Finnish effluents, storm water, landfill leachate and sludge. Environ Sci Pollut Res. doi:10.1007/s11356-013-1518-Z

Prevedouros K, Cousins IT, Buck RC, Korzeniowski SH (2006) Sources, fate and transport of perfluorocarboxylates. Environ Sci Technol 40:32-44

Trudel D, Horowitz L, Wormuth M, Scheringer M, Cousins IT, Hungerbühler K (2008) Estimating consumer exposure to PFOS and PFOA. Risk Anal 28:251-269

UNEP (UN Environment Programme) (2009) Governments unite to stepup reduction on global DDT reliance and add nine new chemicals under international treaty. [cited 2010 December 11]. http://chm.pops. 
int/Convention/Pressrelease/COP4Geneva8May2009/tabid/542/ language/en-US/Default.aspx. Accessed 19 Aug 13

Vestergren R, Orata F, Berger U, Cousins IT (2013) Bioaccumulation of perfluoroalkyl acids in dairy cows in a naturally contaminated environment. Environ Sci Pollut Res. doi:10.1007/s11356-0131722-x

Vestergren R, Cousins IT, Trudel D, Wormuth M, Scheringer M (2008) Estimating the contribution of precursor compounds in consumer exposure to PFOS and PFOA. Chemosphere 73:1617-1624

Wallington TJ, Hurley MD, Xia J, Wuebbles DJ, Sillman S, Ito A, Penner JE, Ellis DA, Martin J, Mabury SA, Nielsen OJ, Andersen MPS (2006) Formation of C7F15COOH (PFOA) and other perfluorocarboxylic acids during the atmospheric oxidation of 8:2 fluorotelomer alcohol. Environ Sci Technol 40:924-930

Xie Z, Zhao Z, Möller A, Wolschke H, Ahrens L, Sturm R, Ebinghaus R (2013) Neutral poly- and perfluoroalkyl substances in air and seawater of the North Sea. Environ Sci Pollut Res. doi:10.1007/s11356-013$1757-\mathrm{z}$

Yamashita N, Taniyasu S, Petrick G, Wei S, Gamo T, Lam PK, Kannan K (2008) Perfluorinated acids as novel chemical tracers of global circulation of ocean waters. Chemosphere 70:12471255

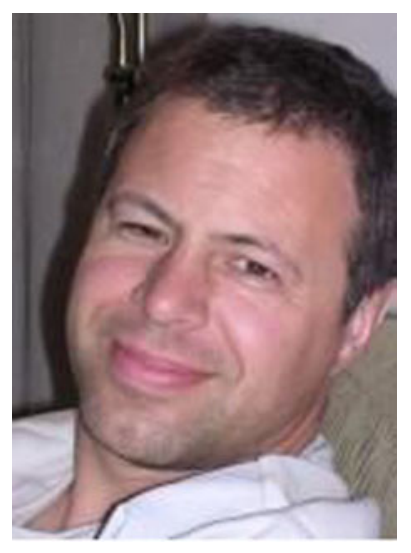

Ian Cousins is a professor in the Department of Applied Environmental Science (ITM) at Stockholm University in Sweden. He earned his $\mathrm{PhD}$ in Environmental Science at Lancaster University in the UK in 1999 and undertook postdoctoral studies in Canada. He is an expert on modelling organic pollutants and has undertaken the first global multimedia modelling studies on perfluoroalkyl substances (PFASs). The aim of Professor Cousins' research is to develop a quantitative and mechanistic understanding on the sources, fate and exposure of organic pollutants in the environment. To achieve this goal, members of his research group develop and apply a range of computer-based, mathematical modelling tools which can be used to predict the physical-chemical properties, environmental fate, bioaccumulation, human exposure and toxicokinetics of organic pollutants. Professor Cousins is a coordinator of the Nordfluor network and the editor of this special issue that resulted from the network's ongoing research activities on PFASs. 